\title{
Congenital Alopecia
}

National Cancer Institute

\section{Source}

National Cancer Institute. Congenital Alopecia. NCI Thesaurus. Code C35790.

A cong enital condition characterized by the absence of hair on the scalp or entire body.

The lack of hair is rarely absolute and is usually accompanied by incompletely grown, lanugo-like hair. It affects males twice as much as females and a familial tendency is common. 